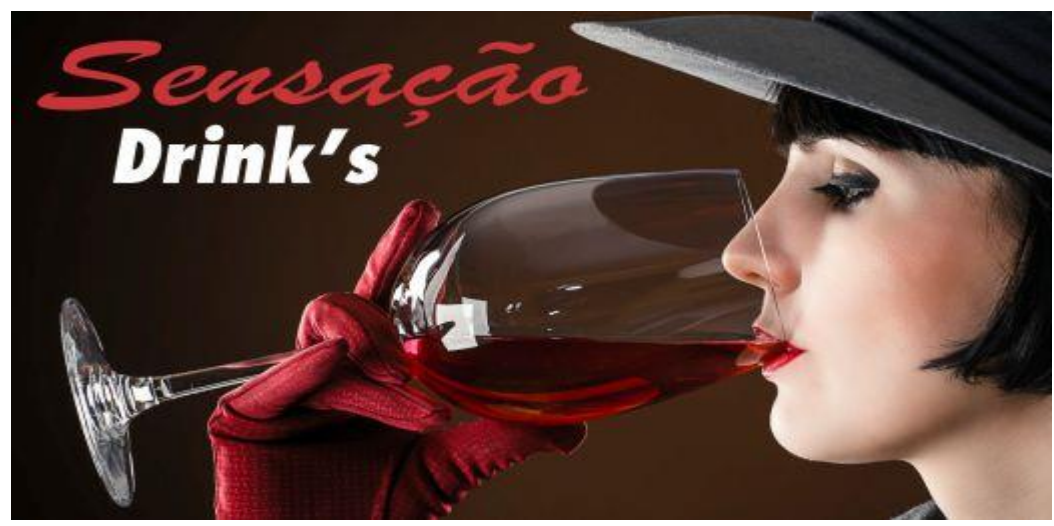

\title{
As casas de prostituição como espaços de significação na cidade ${ }^{1}$
}

Houses of prostitution as meaningful spaces in the city

\author{
Wagner Ernesto Jonas Franco ${ }^{2}$ \\ https://orcid.org/0000-0003-2913-1832
}

\begin{abstract}
Resumo:
Tendo como fundamentação teórica a Semântica da Enunciação em seu diálogo com a Análise de Discurso francesa, este trabalho objetiva compreender sentidos de casas de prostituição enquanto espaços de significação na cidade. Recortamos como corpus sete placas de indicação de casas de prostituição em uma cidade no sul de Minas Gerais. Analisamos as casas de prostituição enquanto espaços heterotópicos na cidade e analisamos os nomes das casas de prostituição enquanto enunciados que integram textos. Concluímos que as casas de prostituição investem-se de sentidos de ilegalidade e desautorização. Os sentidos dos nomes das casas de prostituição mostram uma dominação do homem enquanto consumidor e a objetificação da mulher enquanto produto a ser consumido.
\end{abstract}

Palavras-chave: casas de prostituição. Espaços. Significação.

\begin{abstract}
:
Having as theoretical framework the Semantics of Enunciation in its dialogue with the French Discourse Analysis, this work aims to understand the meanings of houses of prostitution as spaces of meaning in the city. We cut as a corpus seven prostitution houses signs in a city in the south of Minas Gerais. We analyze the houses of prostitution as heterotopic spaces in the city and we analyze the names of houses of prostitution as statements that integrate texts. We conclude that the houses of prostitution are invested with meanings of illegality and discredit. The meanings of the names of the houses of prostitution show a domination of the man as a consumer and the objectification of the woman as a product to be consumed.
\end{abstract}

Keywords: houses of prostitution. Spaces. Meaning.

\footnotetext{
${ }^{1}$ Meus agradecimentos à professora $\operatorname{Dr}^{a}$ Ana Cláudia Fernandes Ferreira pela atenta leitura deste texto.

${ }^{2}$ Doutorando em Linguística pela Universidade Estadual de Campinas (Unicamp). Endereço: Rua Sérgio Buarque de Holanda, 571 - Cidade Universitária, Campinas - SP, 13083-859. E-mail: dominiumwagner@yahoo.com.br
} 


\section{Introdução}

Há espaços na cidade que se significam pela sua centralidade e há espaços que (se) significam por sua marginalidade. As casas de prostituição pertencem a estes últimos lugares. Geralmente, localizadas em rodovias longe dos centros urbanos, essas casas são significadas como fora da cidade. Mas, os limites da cidade são muito tênues. Por vezes, o que está fora e o que está dentro da cidade são ditos pela dicotomia urbano/rural. ${ }^{3}$ No entanto, mesmo significando como fora da cidade, as casas de prostituição pertencem à cidade. São produzidas pela cidade.

Com uma pequena pesquisa na internet, pode-se constatar que as casas de prostituição são conhecidas por seus diferentes nomes: lupanar, prostíbulo, privê, bordel, zona, casa da luz vermelha, casa das primas, casa de facilidades, cabaré, puteiro, etc. Da perspectiva materialista e não referencialista que trabalhamos - a Semântica do Acontecimento em seu diálogo com a Análise de Discurso - essas diferentes nomeações não são apenas formas diferentes de se referir a um mesmo objeto. A nomeação é uma relação de linguagem, uma construção de sentido que identifica objetos para os sujeitos. Os falantes de uma língua, ao ocuparem lugares sociais distintos na cena enunciativa, apropriam-se do real enquanto significado pelo exercício da linguagem (GUIMARÃES, 2007).

Este trabalho tem como objetivo analisar os sentidos presentes em sete placas com nomes de casas de prostituição em uma cidade do sul de Minas Gerais. São seis casas no total, uma com duas placas de identificação. Cinco dessas casas estão localizadas à beira de rodovias nessa cidade. Em um primeiro movimento analítico, utilizando, principalmente, o conceito de heterotopia de Foucault (1984/2015 ${ }^{4}$, buscamos compreender os sentidos circunscritos aos prostíbulos ${ }^{5}$, enquanto espaços de significação, na sua relação com a cidade. No segundo movimento analítico, valendonos de conceitos da Semântica do Acontecimento, buscamos compreender os sentidos

\footnotetext{
${ }^{3}$ Orlandi (2004) diz que há uma sobredeterminação do urbano sobre a cidade de modo que o discurso do urbano silencia o real da cidade. Essa sobredeterminação produz um efeito de verticalização das relações horizontais na cidade e esta se transforma em espaço social hierarquizado. No processo de verticalização, as diferenças, verticalizadas, significam-se pela remissão categórica a níveis de dominação. De nossa parte, acrescentamos que as casas de prostituição estão na ordem de um invisível e de um dominado na cidade.

${ }^{4}$ Este texto de Foucault é resultado de uma conferência proferida por ele em 1967 e publicada na revista Architecture, mouvement, continuité, em 1984. A data de 2015 refere-se à obra por nós consultada. Utilizaremos as duas datas (1984/2015) ao longo do trabalho.

${ }^{5}$ Utilizaremos os nomes "casas de prostituição" e "prostíbulos" sem diferenciação semântica neste trabalho.
} 
presentes nos nomes desses seis prostíbulos enquanto enunciados que integram texto (GUIMARÃES, 2002). Temos a hipótese de que as casas de prostituição reproduzem sentidos sociais de dominação do homem sobre a mulher.

\section{A casa de prostituição como uma heterotopia}

Foucault (1984/2015) coloca o século XX como uma época importante para a discussão sobre o espaço. Hoje, em pleno século XXI, suas reflexões são ainda atuais. O autor afirma que o espaço tem uma história e pode-se retraçar a história do espaço. $\mathrm{Na}$ Idade Média, havia um conjunto hierárquico de lugares: lugares sagrados e profanos, lugares protegidos e desprotegidos, lugares urbanos e rurais.

A partir do século XVII, há uma mudança na compreensão do espaço. Galileu retira a Terra do centro do universo e estabelece, assim, um "espaço infinito e infinitamente aberto" (FOUCAULT, 1984/2015, p. 429). O espaço, a partir do século XVII, é o da extensão e não mais o da localização.

Mas, no século XX, para Foucault, o espaço é definido por suas relações de proximidade entre os pontos e os elementos. Mais concretamente, a questão do espaço define-se em termos de demografia. Importa para o homem saber sobre suas relações de vizinhança, de circulação, de classificação, identificação de elementos humanos para conseguir um dado fim. Trazendo a reflexão para a atualidade, pode-se dizer que as palavras de Foucault ecoam nas de Orlandi (2004) quando esta diz que as relações sociais são relações de sentido.

O espaço não é vazio e homogêneo, mas investido de qualidades, sonhos, paixões. O espaço é volúvel, etéreo, heterogêneo.

Não vivemos em uma espécie de vazio, no interior do qual se poderiam situar os indivíduos e as coisas. Não vivemos no interior de um vazio que se encheria de cores com diferentes reflexos, vivemos no interior de um conjunto de relações que definem posicionamentos irredutíveis uns aos outros e absolutamente impossíveis de ser sobrepostos (FOUCAULT, 1984/2015, p. 431).

Entre os tipos de espaços discutidos por Foucault, interessa-nos mais propriamente o que ele designa por heterotopia, que são espaços reais presentes em todas as civilizações, em todas as culturas. As heterotopias representam, mas contestam e até mesmo invertem o funcionamento dos outros espaços da cidade, uma vez que elas são completamente diferentes desses espaços. Faremos nossa reflexão considerando a casa de prostituição como uma heterotopia. 
As casas de prostituição são "heterotopias de crise" (FOUCAULT, 1984/2014, p. 432), que são espaços reservados à expressão de um comportamento (no caso, a atividade sexual) que é indesejado, mal visto, aos olhos de uma sociedade como a nossa onde o sexo é autorizado apenas entre o marido e sua esposa, ou seja, apenas casais heterossexuais casados são autorizados a esta atividade. Na nossa sociedade, o sexo ainda tem uma característica sacramentada, fortemente influenciada pela Igreja.

A localização das casas de prostituição no espaço da cidade é ilustrativa de seu funcionamento heterotópico. Elas são situadas, geralmente, às margens de uma cidade, à beira de rodovias e adentrando uma estrada vicinal. A sinalização dessas casas também é diferente de outros tipos de sinalização. No nosso corpus, percebemos que se trata sempre de uma placa simples e pequena, de um a dois metros, com o nome do estabelecimento seguido da palavra "boite" ou "drinks", por exemplo, acrescido de uma imagem de uma mulher sensual. A sinalização de outros estabelecimentos na cidade, como a de um motel ${ }^{6}$, possui cores mais fortes, com luminosos e as placas são maiores. Como, no Brasil, é proibido manter estabelecimentos em que ocorra exploração sexual, a oferta do sexo nunca é explícita nas placas de uma casa de prostituição, mas sempre sugerida.

Façamos uma comparação da localização dos prostíbulos com outro espaço muito comum a todas as cidades: a igreja. Estas estão localizadas, frequentemente, nos centros das praças ou no alto de uma colina, ou seja, são bem visíveis a todos. As igrejas também são acessíveis aos cidadãos de todas as idades. Pode-se adentrar esses espaços a qualquer hora, desde que abertas, com família, amigos ou individualmente, geralmente, sem pagar por isso. As igrejas são entendidas, e/ou explicadas, como espaço de oração e retidão aos cidadãos desde a tenra infância. Em outras palavras, a igreja é, hoje, no Brasil, um espaço socialmente aceito, autorizado, hierarquicamente superior aos prostíbulos. Todas as contradições e os conflitos que fazem parte do processo de constituição das igrejas são apagados da história.

Carolina Fedatto (2013) faz uma análise sobre a centralidade da igreja para a constituição de um saber nacional. A autora diz que, em territórios colonizados, a igreja exerceu papel fundante da unidade urbana. O motor da construção da cidade se dava a partir do núcleo religioso e o saber aí legitimado. Saberes ligados à espiritualidade, aos

\footnotetext{
${ }^{6} \mathrm{O}$ motel também é considerado uma heterotopia de crise, mas seu funcionamento hoje na sociedade é mais autorizado que o de uma casa de prostituição. Externamente, ele chama a atenção de todos, localizam-se inclusive em áreas centrais da cidade. Internamente, seu funcionamento se dá pela invisibilidade: há todo um arranjo estrutural para não ver e não ser visto neles.
} 
bons costumes e à "identificação pelo saber (d)a fé" (FEDATTO, 2013, p. 122). Diz ainda a autora:

a igreja impõe sua memória católica/catequizadora/salvadora através do arquivo de seu nome e de sua arquitetura e as autoridades políticas garantem as condições administrativas e financeiras para a estabilização de sua presença na cidade através da centralidade e visibilidade da igreja (FEDATTO, 2013, p. 130, grifos da autora).

Os prostíbulos parecem se inscrever em sentidos opostos aos da igreja: são locais não autorizados, ilegais, marginais, comumente conhecidos como "locais de perdição". E a igreja seria então o "local da salvação". Ainda, os prostíbulos não são de acesso livre a todos e em qualquer idade. Bem como sua localização não é visível a todos e, em geral, é a partir de certa idade que os sujeitos da cidade tomam conhecimento desses locais. Normalmente, não se diz a uma criança que o prostíbulo é o espaço onde o sexo é ofertado em troca de dinheiro.

Percebemos um juridismo (Lagazzi, 1988) no espaço de funcionamento das casas de prostituição. As instituições jurídicas regulam a idade mínima para a entrada em uma casa noturna, mas, nas relações interpessoais cotidianas, as leis de regulamentação podem ou não ser obedecidas. A tensão entre a regulamentação jurídica e o juridismo é constitutiva: o proprietário da casa noturna obedece à lei, mas não quer perder um possível cliente.

A entrada pela primeira vez em um prostíbulo, muitas vezes, faz parte de um processo ritualístico, típico às heterotopias, em que, ao completar certa idade, o menino passaria a ser considerado como homem e teria sua primeira relação sexual com uma prostituta.

Há sentidos moralizantes circunscritos à igreja e aos prostíbulos. Visibilidade e centralidade estão ligadas à igreja, construídas em arquiteturas quase sempre imponentes, centros de peregrinação e turismo pelo mundo todo enquanto os prostíbulos são marginais e invisíveis.

De acordo com Pfeiffer (1997), na história do urbanismo, o século XIX é fundante da conciliação entre os aspectos estético e técnico no surgimento e crescimento das cidades dessa época. Nesse período, surge a metáfora da cidade como organismo, uma metáfora presente em diversas áreas do conhecimento e que coroa uma perspectiva positivista de se pensar a cidade. Além disso, durante o século XIX, há uma maior intervenção saneadora do Estado nas cidades. Os agentes do Estado adentravam casas particulares para alteração de suas estruturas e higienização. 
Ainda segundo Pfeiffer (1997), também no século XIX, o urbanismo toma um caráter disciplinador que possibilita a convivência em uma sociedade marcada por certas regras e interesses. Assim, pensa-se em um modelo ético a ser seguido pelos cidadãos. A cidade, através de seu meio físico, conforma os cidadãos à sua moral. Dessa forma, acrescentamos que os espaços dos prostíbulos, na cidade, são marginais porque não condizem com uma estética e uma funcionalidade de uma cidade orgânica, onde os estabelecimentos exercem uma determinada função que visam, imaginariamente, a um progresso moral conjunto.

O discurso urbano, aliado ao discurso do Estado, investe-se de uma moralidade e de uma correção que ditam como as pessoas devem viver, onde devem circular, quais espaços frequentarem e quais atividades praticar. As diversas práticas sociais e seus rituais são vistos sempre a partir da hierarquização das relações sociais. Se não praticarmos o que foi estabelecido como correto pelo discurso urbano, estamos em crise com a sociedade. Há em funcionamento nos discursos citados uma "tirania da igualdade" (PFEIFFER, 2001, p. 29) que apaga a diversidade e produz o ideal de um mesmo sujeito.

É também no início do século XIX que se dá o aumento do número de prostíbulos no Brasil devido ao fim da escravidão. Muitas mulheres negras e mulatas viam a prostituição como único caminho para garantir seu sustento. No Rio de janeiro, a criação de prostíbulos, nessa época, se dá como medida de controle do aumento excessivo da prostituição nas ruas da cidade (SOARES, 1992).

Contrariamente ao que se comumente pensa, os prostíbulos não existem desde sempre. Eles surgiram junto com a urbanização. Os primeiros relatos de mulheres que se vendiam por dinheiro ocorreram na Babilônia, há cerca de 2400 anos.

Os prostíbulos possuem um caráter único na cidade porque talvez sejam os únicos espaços que não fazem distinção de classe social, raça, cor, beleza, idoneidade, ou qualquer outra característica definidora de seu frequentador. Por fim, para entrar em um prostíbulo, basta-se que se tenha o valor em dinheiro necessário para pagar os serviços que a casa oferece.

Ao situarem-se às margens da cidade, as casas de prostituição investem-se de sentidos do não normatizado, do não regulado, do fora da lei, da ordem e do socialmente aceito.

Foucault (1984/2015, p. 433) menciona que as heterotopias de crise estão em vias de desaparecimento e dando lugar às "heterotopias de desvio", "aquela na qual se 
localiza os indivíduos cujo comportamento desvia em relação à média ou à norma exigida". Como exemplo, ele cita as casas de repouso, as prisões e as clínicas psiquiátricas. De nossa parte, é possível dizer que ambas as heterotopias dão um caráter temporário ao comportamento desviante como se essas instituições tivessem uma função corretiva, ou seja, tão logo passasse a crise ou o comportamento desviante fosse corrigido, aqueles que o praticam poderiam ser realocados à normalidade citadina. Os sujeitos, então, estariam autorizados a conviver em uma sociedade que tem o centro da cidade como um parâmetro de existência correto. Igualmente, pode-se dizer que Foucault coloca os praticantes de sexo não autorizado na mesma relação daqueles que não produzem para a sociedade capitalista: os idosos, os criminosos e os mentalmente incapazes.

Um outro importante conceito proposto por Foucault para se pensar a heterotopia é o de "heterocronia". Isto é, tempos outros que rompem com o tempo tradicional, recortes temporais que se desencaixam da aparente ordem linear cronológica. Ao refletirmos sobre este conceito em relação aos prostíbulos, podemos perceber que eles não fazem parte da rotina inserida na vida de todos os sujeitos. Uma ida a uma casa de prostituição não é um acontecimento que se dá abertamente a todos ${ }^{7}$.

\section{Os nomes das casas de prostituição e seus efeitos de sentido}

Quando tomamos a nomeação de construções urbanas como lugar de reflexão, podemos dizer que a produção de uma referência no espaço tem a ver com a simbolização desse espaço: o modo como um nome (se) projeta (em) outros, identificando o espaço e recortando uma sua memória. (FEDATTO, 2013, p. 114).

De saída para a nossa reflexão sobre nomes de casas de prostituição enquanto enunciados que integram texto (GUIMARÃES, 2002), trazemos a definição de Guimarães (2002, p. 18) de espaço de enunciação:

espaços de funcionamento de línguas, que se dividem, redividem, se misturam, desfazem, transformam por uma disputa incessante. São espaços "habitados" por falantes, ou seja, por sujeitos divididos por seus direitos ao dizer e aos modos de dizer.

\footnotetext{
${ }^{7} \mathrm{Na}$ nossa sociedade, fortemente ligada a uma realidade virtual proporcionada pelas redes sociais, é difícil presenciar alguém postar fotos, vídeos ou comentários de uma ida a um prostíbulo, como acontece quando alguém vai a shows, baladas e outros eventos.
} 
Não é a língua somente que produz a significação, mas ela na relação com o falante. Os espaços de enunciação são espaços políticos de funcionamento linguístico. Ou seja, são espaços de conflitos e disputas pelas palavras e pelas línguas, espaços de "conflito entre uma divisão normativa e desigual do real e uma divisão pela qual os desiguais afirmam seu pertencimento" (GUIMARÃES, 2002, p. 16). O político é parte do funcionamento das línguas. Como diz Zoppi Fontana (2012, p. 7): "Por ser necessariamente atravessada pelo político, a língua é marcada por uma divisão, pela qual os falantes se identificam".

O falante, por sua vez, não é o indivíduo físico que realiza o ato de falar, mas uma "figura política constituída pelo espaço de enunciação" (GUIMARÃES, 2002, p. 18). O funcionamento da língua, no espaço de enunciação, agencia o falante a falar, produzindo o acontecimento $^{8}$ da enunciação. Falar não é uma prática individual e subjetiva, mas uma prática política. Enuncia-se em um espaço de enunciação que é determinado historicamente com relação sempre dividida entre línguas.

Segundo Guimarães (2011), no acontecimento de enunciação, o falante é tomado como Locutor (L), que é o lugar que se representa no próprio dizer como sua fonte. Mas, a figura do Locutor não é una e homogênea, há uma disparidade constitutiva entre o Locutor e os lugares sociais autorizados a falar que afetam o Locutor: "para o Locutor se representar como origem do que se enuncia, é preciso que ele seja agenciado por um lugar social de locutor" (GUIMARÃES, 2011, p. 23). Esse lugar social, o autor denomina de locutor- $x$, onde x é a variável que representa esse lugar social (professor, presidente, governador etc).

O Locutor e o locutor-x são figuras enunciativas fundamentais para a compreensão da cena enunciativa, que são "modos específicos de acesso à palavra dadas as relações entre figuras de enunciação e as formas linguísticas" (GUIMARÃES, 2002, p. 23). É na cena enunciativa que se percebe o funcionamento do acontecimento. Compreender a cena enunciativa é compreender o próprio modo de constituição dos lugares do Locutor e do locutor-x pelo funcionamento da língua.

\footnotetext{
${ }^{8} \mathrm{O}$ acontecimento, segundo Guimarães (2011, p. 15), “é o que faz diferença na sua própria ordem. E o que especifica este acontecimento é a temporalidade que ele constitui. Assim, um acontecimento não é considerado em virtude de estar num certo momento do tempo, antes de um outro acontecimento também no tempo. Não é este aspecto que considero como especificador de um acontecimento. O que especifica um acontecimento é a temporalidade que ele constitui: um passado, um presente e um futuro. Ou seja, um acontecimento é distinto de outro acontecimento porque ele recorta um passado de sentidos que convive com o presente da formulação do Locutor e assim traz uma projeção de futuro de sentidos que não significariam não fosse o acontecimento em questão".
} 
Na composição da cena enunciativa ainda deve-se considerar os lugares de dizer, ou seja, os enunciadores, que são figuras que "representam no acontecimento enunciativo (e portanto nos enunciados nele produzidos) diversos modos de apagamento do lugar social do locutor" (ZOPPI FONTANA, 2012, p. 9). Em outras palavras, o lugar de dizer representa o apagamento do político (no sentido de disputa pelas palavras) no acontecimento enunciativo.

Os enunciadores podem ser representados a partir de um lugar de dizer individual, coletivo, genérico e universal. Os enunciadores caracterizam-se pelos seguintes aspectos: no enunciador individual, um o locutor apresenta-se como um indivíduo específico que diz para um indivíduo também específico. No enunciador coletivo, diz-se a partir de um lugar corporativo, de um conjunto que o dizer apresenta como um todo específico. O enunciador genérico é próprio de provérbios e ditados populares. No enunciador universal, há um sentido de universalidade, um dizer que é voltado para todos.

Exemplifiquemos esse conceito com a seguinte citação:

Nada impede que da posição de sujeito científico o lugar do dizer seja o enunciador-universal e o lugar social seja o de locutor-presidente. Tantas vezes o atual presidente [FHC na época] mobilizou argumentações próprias da economia, da sociologia, etc. enunciando do lugar de presidente. Mas não deixa de ser interessante ver como falar do lugar do presidente a partir de uma posição do discurso científico é diferente de falar do lugar do presidente a partir de uma posição do discurso jurídico (GUIMARÃES, 2002, p. 31).

A cena enunciativa não é unívoca. Tem-se para ela a seguinte configuração: um Locutor com seu correlato, o Alocutário. Um locutor-x com seu correlato, o alocutáriox. e o enunciador com seu correlato, o destinatário.

\section{A nomeação dos prostíbulos no espaço de enunciação}

Em concordância com o que propomos realizar, percebemos que a nomeação de uma casa de prostituição se dá no espaço de funcionamento das línguas inglesa, francesa (nas palavras boite/boate) e portuguesa. A língua inglesa é mais frequente nas nomeações e em outros enunciados dos textos. Na relação hierarquizada entre as línguas no espaço de enunciação, a língua inglesa ocupa um grau superior.

A língua inglesa neste espaço funciona como a língua do capitalismo, agregando um valor de mercado ao estabelecimento. Nomear uma casa de prostituição é nomear 
um estabelecimento comercial. Sendo um estabelecimento comercial, há a oferta do sexo como produto. No entanto, essa oferta não é feita de forma explícita nas placas dos nomes das casas à beira das estradas. A oferta do sexo está lá, mas de forma velada. É preciso que uma memória ${ }^{9}$ de sentidos preencha o acontecimento do texto/placa a ler.

Nomeiam-se as casas a partir do locutor-proprietário, inserido no discurso capitalista, e o lugar de dizer desse locutor é o individual. Os nomes que nos propomos a analisar são os seguintes: Arletts American Bar, Boite Scorpions, Hawaianas Shows, Sensação Drink's, Cowboy Drinks e Erótica Drinks. Esses nomes são compreendidos como enunciados que integram textos, no caso, as placas de identificação dessas casas, fixadas à beira das estradas ou em anúncios na internet. Outros enunciados que compõem as placas também podem fazer parte da análise, na medida em que lançam luz aos sentidos desses estabelecimentos na cidade.

Utilizamos aqui um procedimento de análise próprio à Semântica do Acontecimento. Esta disciplina propõe-se a analisar enunciados, entendidos como unidades que integram textos. $\mathrm{O}$ enunciado é um elemento linguístico com forma, ou seja, é constituído por sintagmas, e tem sentido. $\mathrm{O}$ enunciado possui duas características: ele tem uma consistência interna e uma independência relativa em relação às outras sequências linguísticas que com ele integram texto (GUIMARÃES, 2011).

O texto, por sua vez, é entendido como unidade de sentidos integrada por enunciados. O texto não é unidade no sentido de ser uno, unívoco. Sua interpretação está sempre aberta, já que há uma disparidade entre o acontecimento da produção do texto e o acontecimento de sua leitura. $\mathrm{O}$ texto interessa a uma abordagem enunciativa na medida em que certas categorias são pensadas na relação com este objeto sóciohistórico.

Pensemos duas destas categorias: a reescrituração e a articulação, procedimentos de produção de sentidos no acontecimento da enunciação. Segundo Guimarães (2013), a articulação é o procedimento que explica como as formas simbólicas significam pela sua contiguidade ao integrarem texto. É um procedimento de relação entre as formas a nível local, no interior do enunciado. É um procedimento enunciativo, portanto exime-se de remeter o enunciado a um sistema linguístico maior.

\footnotetext{
${ }^{9}$ A memória discursiva ou interdiscurso é definida por Orlandi (2010) como saber discursivo que torna possível todo dizer.
} 
A articulação pode se dar por três modos distintos: por dependência, por coordenação, por incidência. A articulação por dependência se dá quando os elementos contíguos se organizam por uma relação que constitui, no conjunto, um só elemento ou grupo nominal. A articulação por coordenação toma elementos de mesma natureza e os organiza como se fossem um só da mesma natureza de cada um dos constituintes. A articulação por coordenação se apresenta por um processo de acúmulo de elementos numa relação de contiguidade. E a articulação por incidência se dá entre um elemento de uma natureza e outro de outra natureza, de modo a formar um novo elemento do tipo do segundo. Esta última é uma relação entre um elemento e outro sem uma relação de dependência estabelecida.

Agora, a reescrituração é o procedimento pelo qual a enunciação de um texto rediz insistentemente o que já foi dito. É uma volta ao dito para continuar dizendo no batimento entre paráfrase e polissemia ${ }^{10}$. A reescritura faz com que algo dito signifique como diferente de si. Não é um procedimento que se dá apenas pela linearidade do texto, mas também pode ser construído de forma transversal.

Nas palavras de Guimarães (2002, p. 28):

A reescrituração é uma operação que significa, na temporalidade do acontecimento, o seu presente. A reescrituração é a pontuação constante de uma duração temporal daquilo que ocorre. E ao reescriturar, ao fazer interpretar algo como diferente de si, este procedimento atribui (predica) algo ao reescriturado. E o que ele atribui? Aquilo que a própria reescrituração recorta como passado, como memorável. [...] E esse movimento de predicação na duração do presente pelo memorável significa porque projeta um futuro, o tempo da interpretação no depois do acontecimento no qual o reescriturado é refeito pelo reescriturante.

Voltando a falar das placas como textos, percebemos, inicialmente, que palavras da língua inglesa articulam-se em todos os nomes das casas de prostituição e em outros enunciados (como strip-tease). Mas, o funcionamento da língua inglesa nos nomes não se dá na ordem do gramaticalmente correto. O funcionamento da língua inglesa está na ordem de uma memória da língua ${ }^{11}$ (PAYES, 2006). O modo como as palavras nos nomes se articulam não segue estritamente a sintaxe nem da língua inglesa nem da

\footnotetext{
${ }^{10}$ A tensão entre paráfrase e polissemia é constituinte de qualquer discurso. A paráfrase refere-se ao mesmo dizer sedimentado e a polissemia refere-se ao diferente, ao rompimento, "essa força na linguagem que desloca o mesmo, o garantido, o sedimentado" (ORLANDI, 1988/2011, p. 27).

${ }^{11}$ Segundo Payer (2006), a memória da língua é tomada a partir da língua em sua relação de significação com a história. Ela implica sujeitos e os diferentes modos de fazer de a língua significar por sua história. É a história fazendo a língua significar.
} 
língua portuguesa. Essas línguas estão nos textos transformadas, mostrando que, no espaço de enunciação, não há um mero transporte de uma língua a outra. Falaremos mais sobre isso adiante.

A palavra mais recorrente na articulação dos nomes dessas casas e de outras que não citamos aqui é drinks (por vezes, drink's), bebida alcoólica, em inglês. Drinks nomeia as casas e apresenta-se como um dos produtos que a casa oferece a seus clientes. Bebida alcoólica é um dos produtos principais ofertados nas casas de prostituição. Em muitas dessas casas, os profissionais que lá trabalham, prostitutas ou não, induzem os frequentadores a consumir bebidas em grandes quantidades e, assim, garantirem maiores lucros aos proprietários. O fato de drinks ou drink's estarem escritos em inglês faz parte do jogo de sentidos que funciona juntamente com os nomes dos prostíbulos. Os nomes, escritos na língua internacional do capitalismo, predicam sentidos seguramente mercadológicos nos textos. Mas também, os nomes não apenas nomeiam o lugar, mas adjetivam este lugar. Vejamos como essa adjetivação ${ }^{12}$ funciona.

Figura 1: placa de identificação de uma casa de prostituição

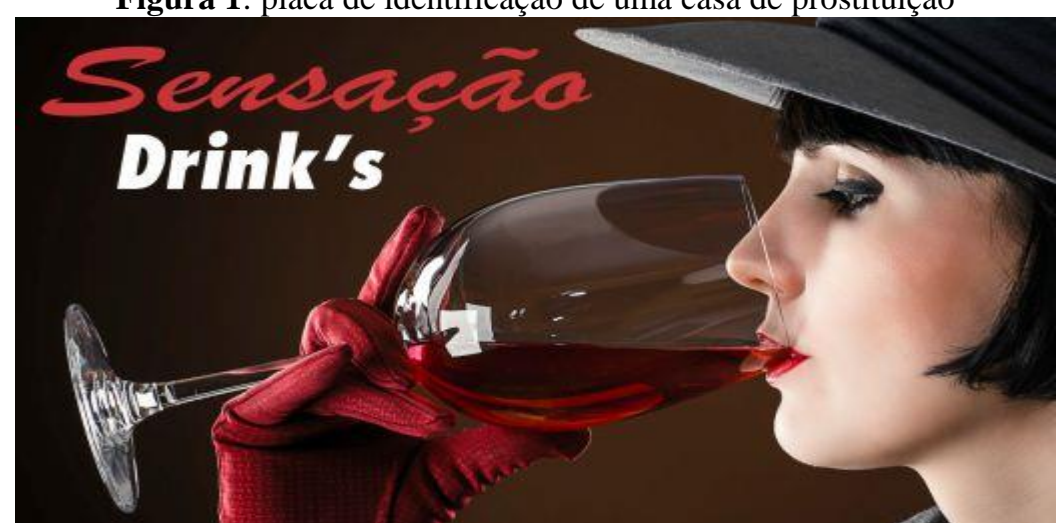

Fonte: http://www.tvminas.com/empresa-info/554/Sensacao_Drinks. Acesso em 15/04/2018

Na figura 1, vemos o nome Sensação escrito em letra cursiva na cor vermelha, uma cor associada à sensualidade, e, logo abaixo, Drink's na cor branca em letra de forma. Ilustrativamente, o rosto de uma mulher branca bem maquiada bebendo uma taça do que aparenta ser vinho. No nome Sensação Drink's, temos uma articulação por dependência em que a enunciação desse nome articula uma palavra da língua portuguesa e uma da língua inglesa. Enunciar Sensação Drink’s produz um presente e uma futuridade de sentidos: o nome de uma casa de prostituição. Ambas as palavras recortam como memoráveis diferentes sentidos. O Locutor, definido como a origem do

\footnotetext{
${ }^{12}$ Adjetivação aqui não está em seu sentido estritamente gramatical, mas no sentido de que o nome da casa de prostituição predica sentidos sobre esta casa.
} 
dizer, integra o texto como unívoco, mas o dizer se divide em dois enunciadores, um para Sensação e outro para Drink's. Vejamos:

E1: Sensação: “impressão produzida pelos objetos exteriores num órgão dos sentidos" $"$.

E2: Drink's: o apóstrofo deveria estar colocado na palavra anterior, indicando o possuidor do objeto, de acordo com a gramática da língua inglesa. Sendo assim, uma possível intenção de sentidos seria indicar os drinks de um lugar nomeado Sensação. Mas não se marca o caso possessivo em uma palavra da língua portuguesa e o apóstrofo é transportado para a próxima palavra em língua inglesa. Como o 's integra o nome de um estabelecimento comercial (um prostíbulo), ele (o ’s) recorta como memorável nomes de estabelecimentos comerciais internacionais (Bob's, McDonald's).

Nomear o espaço de Sensação produz sentidos para este espaço. O que há neste espaço que produz "sensação"? Para responder, propomos as seguintes paráfrases: a) Os drinks são sensacionais. b) O espaço é sensacional. c) As mulheres (prostitutas) são sensacionais. Há, logo de saída aqui, e falaremos mais disso adiante, sentidos que colocam a mulher (no caso, a prostituta) como um "objeto" ou "produto sensacional" que a casa oferece a seus clientes. Drinks e mulheres são, portanto, reescriturações enumerativas $^{14}$ de produtos da casa de prostituição. Em um primeiro Domínio Semântico de Determinação ${ }^{15}$ - DSD -, com foco nos sentidos que a casa predica sobre mulher, temos:

Sensação - sensacional $\dashv$ mulher/prostituta

Procedendo com essa compreensão dos nomes dos prostíbulos em uma dupla articulação de nomeação e de adjetivação, temos os sentidos circunscritos a esses espaços. Vejamos:

Arletts American Bar $^{16}$ : Neste nome, há, igualmente ao anterior, uma articulação por dependência em um enunciado que mistura características da língua portuguesa e da língua inglesa. Ao nome Arlete, normalmente, não se acrescenta s. Esse s está aí como

\footnotetext{
${ }^{13}$ Fonte: www.pliberam.pt. Acesso em 23/09/2017.

14 A enumeração é um tipo particular de reescrituração. É um modo de expansão de um termo ou enunciado no texto (GUIMARÃES, 2009).

${ }^{15}$ Os DSDs são procedimentos de explicitação de sentidos comuns à Semântica do Acontecimento. Eles fazem parte do modo de considerar a produção de sentidos das palavras e dos enunciados enunciativamente. Os sinais $\perp$ ou $\vdash$ significam determina e o sinal - indica uma relação sinonímica (GUIMARÃES, 2002).

${ }^{16}$ As placas desta e da próxima casa de prostituição estavam indisponíveis no momento de escrita deste artigo.
} 
uma memória da língua inglesa. Falta no nome o apóstrofo do caso possessivo. Gramaticalmente correto, o enunciado ficaria: Arllett's American Bar (Bar Americano da Arllett). Como dissemos anteriormente, as línguas se transformam no espaço de enunciação.

A palavra American predica sentidos sobre Bar. Este nome não significa apenas um bar brasileiro com nome em inglês. A evidência da língua inglesa no nome não basta. Há que significar também que toda a estrutura interna do bar seja americana. Assim, A palavra American recorta como memorável sentidos de um espaço outro também geográfico. Um espaço de uma língua outra, a língua estrangeira, o estranho, o exótico, o diferente, a língua estrangeira onde tudo nos é permitido, uma língua de gozo (Prassi, 1998). Propomos o seguinte DSD agora para a casa de prostituição:

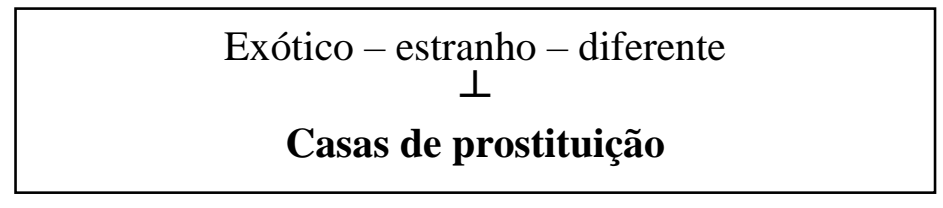

O nome Arletts é um nome feminino de origem francesa (assim como boite) que recorta um memorável bastante significativo para este prostíbulo. Coloca-se em evidência o nome de uma mulher. A proprietária? Em muitos estabelecimentos comerciais, é comum que seus proprietários os nomeiem com os próprios nomes. Também é comum que os prostíbulos sejam gerenciados por mulheres, as chamadas cafetinas ou proxenetas. Que sentidos para o sujeito-mulher essa nomeação coloca? Já não é apenas o sentido presente na placa anterior, ou seja, um objeto que oferta sexo, mas, o de uma mulher que controla essa oferta.

Boite Scorpions: A enunciação deste nome articula um nome em francês Boite e outro em inglês Scorpions, escorpiões, o aracnídeo da cauda fálica através da qual ele inocula seu veneno. Animal peçonhento pequeno, mas perigoso. O que parece estar em jogo aqui são sentidos de atração e risco, força, masculinidade, dominação e mistério. Este nome coloca em evidência sentidos para os possíveis frequentadores do local, homens fortes, dominadores, perigosos, másculos. Lembremos que o nome do livro autobiográfico da ex-prostituta Bruna Surfistinha é O Doce Veneno do Escorpião ${ }^{17}$. Nomear o prostíbulo com o nome de um animal comumente atribuído ao homem produz um sentido animalesco para este homem. Em relação parafrástica, o animal, também

${ }^{17}$ SURFISTINHA, B. O Doce Veneno do Escorpião: O diário de uma garota de programa. $1^{\mathrm{a}}$ edição, 172 páginas; editora Panda Books, 2005. 
pequeno, peçonhento e perigoso, que se atribui à mulher é a "aranha", pejorativamente designando o órgão sexual feminino. Pode-se ver nessas nomeações que há uma relação de dominância do homem sobre a mulher. Propomos então o seguinte DSD agora para os frequentadores:

$$
\begin{gathered}
\text { perigoso }- \text { forte }- \text { misterioso }- \text { dominador }- \text { animal } \\
\perp \\
\text { Homem/frequentador }
\end{gathered}
$$

Na Figura 2, Cowboy drinks, a placa articula elementos importantes para a compreensão de seus sentidos. Esta casa de prostituição localiza-se em um bairro bastante afastado do centro. A localização incide sobre a nomeação da casa. Há um imaginário de sentidos para sua localização (zona rural?) e também para os sujeitos que ali habitam. Na placa, vemos COWBOY DRINKS escrito na cor preta em letra de forma maiúscula em um banner descolorido pelo sol, pendurado em uma cerca de madeira, à beira de uma rodovia, com o enunciado com lindas garotas, escrito também na cor preta em cursiva minúscula logo abaixo do nome. Abaixo deste último enunciado, o telefone do estabelecimento. A cor de fundo do banner é branca. Ao lado do escrito, no banner, tem-se a imagem sombreada de uma mulher de cabelos longos e lisos servindo uma bebida, sentada com as pernas esticadas e cruzadas em uma pose sensual. Ao lado deste banner, está pendurado um outro banner com a imagem de uma mulher jovem vestida com roupa no estilo country em uma pose também sensual. Essas descrições fazem parte das condições de produção dos sentidos desses enunciados.

Figura 2: placa de uma casa de prostituição

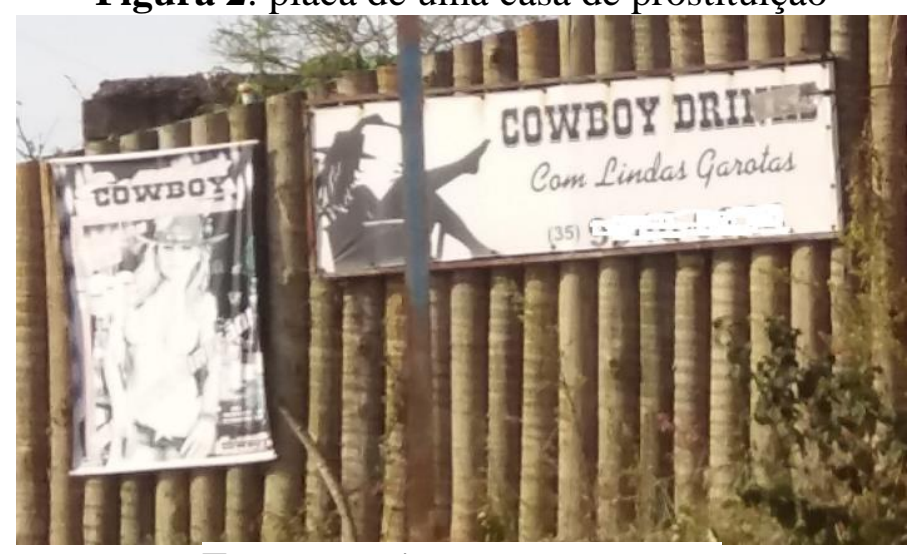

Fonte: arquivo Wagner Franco 
Neste nome, sob a aparente univocidade do Locutor, origem do dizer na cena enunciativa, temos diferentes enunciadores: E1: Cowboy dá nome ao prostíbulo, E2: também é um nome de um tipo de bebida feito com uísque, E3: dá nome à bebida alcoólica consumida pura, geralmente o uísque, sem adicionar qualquer outro ingrediente como água, gelo, sal etc. E4: Cowboy é o vaqueiro - o garoto (boy) da vaca (cow) - aquele que pastoreia, guarda o gado. Cowboy é um substantivo masculino, portanto, configura sentidos para o frequentador masculino do estabelecimento. Cowboy também é o sujeito rústico do campo. Um sujeito forte que está habituado à poeira diária e ao sol forte das estradas de terra dos campos. Aqui, esses sentidos também colocam a mulher em posição inferior ao do homem. A oferta do sexo está presente nas imagens das mulheres e no enunciado Com lindas garotas. Pela forma como esse prostíbulo predica sentidos para seus frequentadores, propomos o seguinte DSD:

$$
\text { Cowboy - homem do campo - rústico - forte }
$$

$\perp$

\section{Frequentador/homem}

A placa se faz texto com três enunciados, o de sua nomeação - Cowboy Drinks o enunciado Com lindas garotas e o telefone de contato. Em Com lindas garotas, temos uma articulação por incidência, "com" é um elemento diferente de "lindas garotas" e, juntos, fazem enunciado no acontecimento da enunciação. Drinks e lindas garotas aparecem como reescriturações enumerativas de produtos ofertados pela casa. Assim como as imagens das mulheres podem ser entendidas como reescriturações por sinonímia de lindas garotas. Tanto é que as seguintes paráfrases são possíveis:

Drinks e lindas garotas são produtos na Cowboy Drinks.

Vamos à Cowboy Drinks, lá tem drinks e lindas garotas.

Ainda podemos dizer que Com lindas garotas é um argumento ${ }^{18}$ para se frequentar a casa de prostituição. A placa evidencia sentidos para seus frequentadores e

\footnotetext{
18 O sentido de argumentação, neste trabalho, é o formulado por Guimarães (2010). Para o autor, a argumentação não diz respeito à persuasão, ela é um "procedimento próprio do funcionamento da textualidade" (GUIMARÃES, 2010, p. 82). Mais recentemente, o autor diz que a argumentação tem um caráter político, é o "processo pelo qual um lugar social de locutor sustenta uma posição na enunciação" (GUIMARÃES, 2013, p. 283).
} 
para os produtos lá ofertados. Lindas e garotas predicam sentidos para a mulher/prostituta. Assim, propomos o segundo DSD:

\section{Linda $\uparrow$ garota $\uparrow$ mulher/prostituta}

Hawaianas Shows: Este nome está em uma placa de metal de cerca de dois metros de largura por três metros de altura, à beira de uma rodovia. Hawaianas Shows está escrito em letra de forma da cor vermelha e sombreado em branco (Figura 3). Logo abaixo do nome, em letra de forma branca, está escrito a localização do prostíbulo $A$ 500 mts. A placa está na entrada de uma estrada sem asfalto em um bairro afastado do centro da cidade. Abaixo de A 500 mts estão elencados os seguintes enunciados: Drinks, Strip Tease, Massagem. Tomando quase toda a placa está uma imagem bastante nítida e bem colorida do torso de uma mulher bronzeada, sorridente, seminua, vestida de trajes havaianos estereotipados: no lugar do sutiã, estão dois cocos cortados ao meio, uma saia com adereços, um colar e um cocar na cabeça. Ela está, aparentemente, na performance da típica dança havaiana Hula. O fundo da placa é preto e há os números de dois telefones celulares.

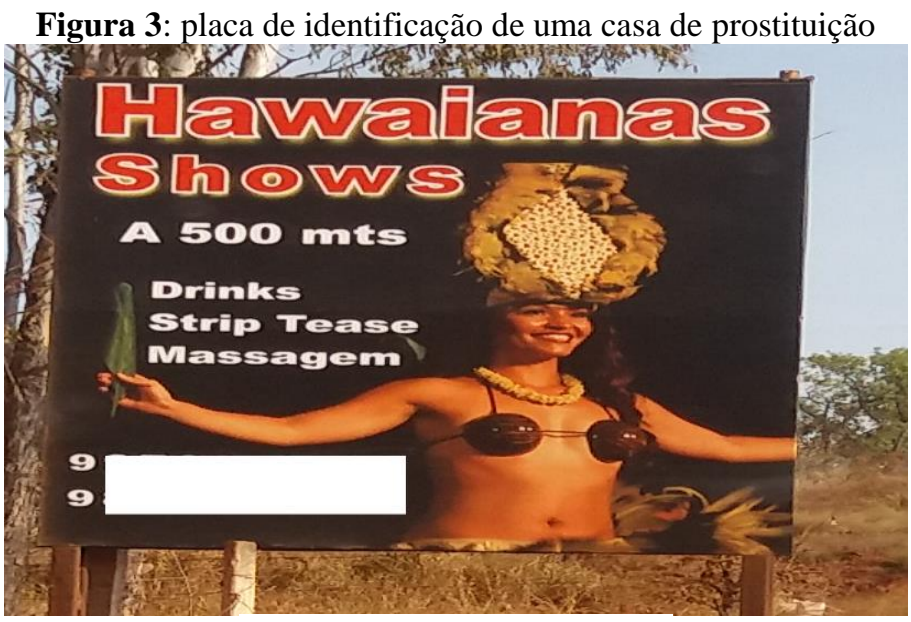

Fonte: arquivo Wagner Franco

Assim como em American, a palavra Hawaianas não significa apenas pela memória da língua inglesa. Ela recorta como memorável uma localização geográfica outra. Um lugar onde algo é possível e que não é possível em nosso próprio lugar. O Havaí é um afastado arquipélago de ilhas paradisíacas nos Estados Unidos. Ao nomear de Hawaianas Shows a casa de prostituição, recorta-se como memorável o isolamento de uma ilha inabitada - espaço afastado dos olhos julgadores da sociedade - e também de seu calor e sua beleza exótica. Recorta-se o memorável da vivência em um estado de natureza selvagem ainda sem regras sociais, um estado de liberdade. 
$\mathrm{Na}$ placa, Hawaianas shows articula-se por dependência e projeta essa futuridade de sentidos: ser o nome de uma casa de prostituição. Mas também o nome apresenta-se como um produto ofertado pela casa. Hawaianas shows, drinks, strip-tease e massagem são reescriturações enumerativas por expansão de produtos. Tanto que a seguinte paráfrase é possível:

Shows com havaianas, drinks, strip-tease e massagem são produtos na Hawaianas Shows.

A imagem da mulher vestida de havaiana é uma reescrituração de hawaianas. A imagem, no funcionamento de uma placa de propaganda, não designa uma pessoa no mundo, ela funciona como um argumento para aqueles que ali querem frequentar. É a imagem de uma mulher exótica, bonita, jovem, sensual e seminua. A imagem da mulher é a caracterização de um produto a ser encontrado na casa. Assim, propomos o terceiro DSD:

$$
\text { Exótica - bonita - jovem - sensual - seminua } \dashv \text { mulher/prostituta }
$$

Erótica Drinks: Este nome aparece em duas placas nas dependências do prostíbulo situado à beira da rodovia (Figuras 4 e 5). Postas à frente e atrás da casa, tanto aqueles que transitam na rodovia à direita ou à esquerda podem identificar a casa como um prostíbulo. Na placa à frente da casa, com cerca de dois metros de altura por três de largura, tem-se o nome ERÓTICA escrito em vermelho em letra de forma maiúscula com maior destaque. Abaixo do nome, está escrito DRINKS também em letra de forma maiúscula, mas com menor destaque. A placa está em fundo branco e preenchendo metade da placa está a foto das nádegas de uma garota usando um short vermelho bastante curto, uma mão (não se pode confirmar se é da garota) segura a barra do short, como que para arrancá-lo. Na parte inferior da placa, o endereço da casa de prostituição. Não há telefone.

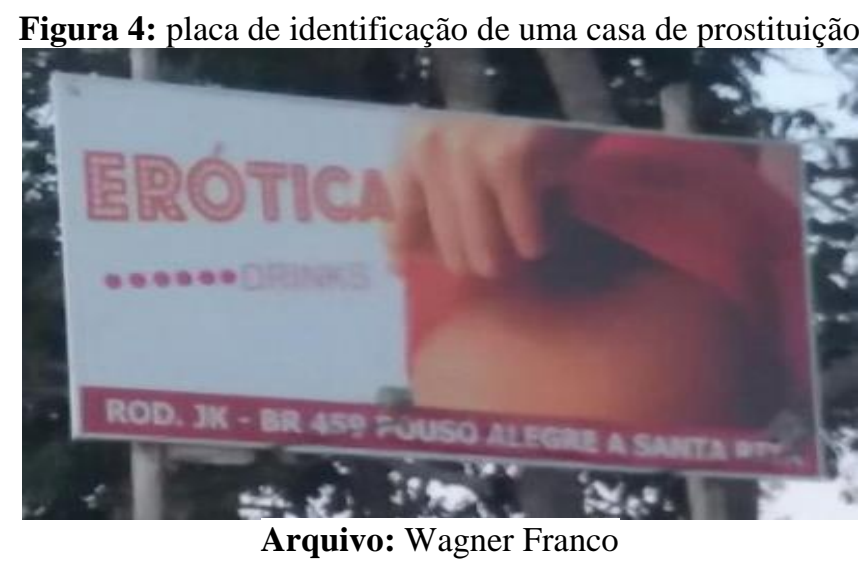




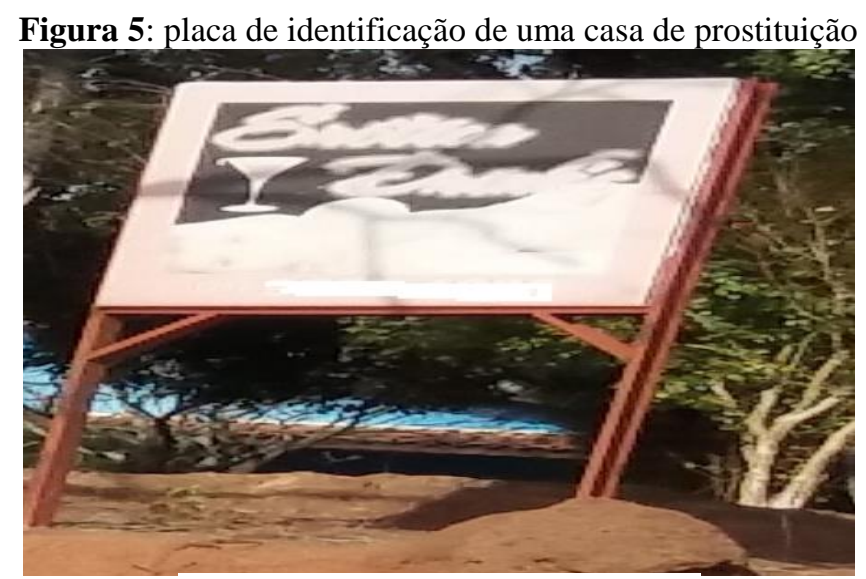

Fonte: arquivo Wagner Franco

A outra placa, atrás da casa, tem um metro quadrado de tamanho e marcas de desgaste pelo sol são mais visíveis que a primeira placa. Em um fundo escuro está escrito erótica drinks em letra cursiva minúscula. Na lateral da placa, o desenho de uma taça de bebida. Na parte inferior da placa, quase invisível devido ao desgaste do sol, a imagem de uma mulher deitada de forma sensual e seminua. Logo abaixo dessa imagem, está um número de telefone.

A articulação do adjetivo feminino no singular erótica e do substantivo em língua inglesa drinks se dá por dependência. Erótica predica sentidos para a casa de prostituição, as bebidas e as prostitutas. Dos nomes analisados, erótica é o adjetivo que recorta mais fortemente o memorável do conteúdo sexual. Poucas casas de prostituição possuem adjetivos em seus nomes. Propomos o seguinte DSD:

\section{Erótica 1 mulher/prostituta}

\section{Considerações finais}

Retomando a cena enunciativa, dissemos que o locutor é agenciado a falar/nomear as casas de prostituição do lugar social de proprietário. Este locutorproprietário nomeia a casa de prostituição agenciado pelo discurso do mercado. $\mathrm{O}$ acontecimento da nomeação é sempre afetado pela história e pelo político, este "caracterizado pela contradição de uma normatividade que estabelece (desigualmente) uma divisão do real e a afirmação de pertencimento dos que não estão incluídos" (GUIMARÃES, 2002, p.16).

A historicidade dos sentidos e o político podem ser melhor compreendidos se pensarmos na figura enunciativa correlata ao locutor-proprietário: o alocutário-x. 
Ressaltemos, primeiramente, que a relação locutor-x/alocutário-x não é pragmática ou da ordem de uma intenção. Ela não é uma relação de interação, é uma relação de historicidade dos sentidos no agenciamento enunciativo de ambos os falantes. Isso porque há uma disparidade do lugar do leitor em relação ao lugar de autor de um texto. "Ser autor e ser leitor são relações constituídas por acontecimentos diferentes relativamente ao mesmo texto" (GUIMARÃES, 2013, p. 203).

Considerando essa disparidade na nossa leitura e análise das casas de prostituição como espaços de significação na cidade e suas nomeações enquanto enunciados que integram textos, podemos nos interrogar: para quem se nomeia uma casa de prostituição? Como a nomeação se dá no espaço do discurso do mercado, o correlato do locutor-proprietário é o alocutário-cliente. Historicamente, os frequentadores/clientes dessas casas são do sexo masculino.

No espaço de enunciação afetado pelo discurso mercadológico, estabelece-se uma relação entre o consumidor (o homem, pelo menos em maioria) e o produto consumido (drinks, massagem, strip-tease, prostitutas...). Nessa relação, predica-se sentidos para esse consumidor do sexo masculino tais como o de força, dominação, virilidade, perigo (veja-se Cowboy e Scorpions). E, para as mulheres, os sentidos são de um "produto" a ser consumido, dominado ${ }^{19}$. As prostitutas devem ser lindas garotas, eróticas, sensuais, sensacionais, diferentes e exóticas.

Cabe dizer que, no espaço de enunciação da nomeação das casas de prostituição, a língua inglesa não funciona apenas como a língua do mercado globalizado. Ao integrar nos textos palavras como cowboy, drinks, Hawaiana, American e shows, os enunciados recortam como memorável um espaço outro ou elementos de um espaço outro onde algo é possível. Vale dizer, portanto, que a heterotopia não significa apenas um espaço físico, mas se dá também na materialidade histórica da língua, na medida em que a linguagem é utilizada para falar de algo que está fora dela. Com a ressalva de que a nossa concepção de linguagem não é referencialista. A construção de sentido é uma relação de linguagem com linguagem. Ao funcionar simbolicamente, a linguagem estabelece a relação com as coisas no mundo (GUIMARÃES, 2009).

Os sentidos explicitados acima são possíveis devido à integração dos nomes das casas de prostituição aos textos em que se encontram, isto é, as placas de identificação

\footnotetext{
${ }^{19}$ A ex-prostituta, Marian Hatcher, hoje, coordenadora de projetos que combatem o tráfico de mulheres, em depoimento sobre a prostituição, disse: "mas muitos dos caras que compram sexo não pagam só pelo ato físico, mas pelo poder sobre alguém como eu". Fonte: http://www.huffpostbrasil.com/marianhatcher/uma-linda-mulher-prostituicao b 6933902.html. Acesso em 19/20/2017.
} 
dessas casas. As placas jogam com imagens, cores, formatos de escrita e arranjo criativo que obedecem ao discurso mercadológico que afeta os outros estabelecimentos comerciais da cidade. A implicação desse arranjo é considerar a mulher como um produto do estabelecimento casa de prostituição. As placas podem localizar-se nas dependências das casas de prostituição, quando estas estão nas beiras das rodovias, ou as placas estão à beira das rodovias e indicam a localização dos prostíbulos, geralmente, adentrando uma estrada vicinal.

\section{Referências}

FEDATTO, C. P. Um saber nas ruas: o discurso histórico sobre a cidade brasileira. Campinas, SP. Editora da Unicamp, 2013.

FOUCAULT, M. (1984). Ditos e Escritos III: Estética: literatura e pintura, música e cinema. Organização e seleção de textos Manoel Barros da Motta; tradução Inês Autran Durado Barbosa. 4 ed. Rio de Janeiro: Forense Universitária, 2015.

GUIMARÃES, E. Semântica do Acontecimento. Campinas: Pontes, 2002.

GUIMARÃES, E. domínio semântico de determinação. In: GUIMARÃES, E. e Mollica, M. C. (orgs). A palavra: forma e sentido. Campinas, Pontes/RG, 2007.

GUIMARÃES, E. A enumeração funcionamento enunciativo e sentido. Caderno de Estudos Linguísticos, № 51, vol. 1, p. 49-68, jan/jun. 2009.

GUIMARÃES, E. Os Limites do Sentido: um estudo histórico e enunciativo da linguagem. Campinas: Editora RG, 4 edição, 2010.

GUIMARÃES, E. Análise de texto. Procedimentos, análises, ensino. Campinas: RG Editora, 2011.

GUIMARÃES, E. Argumentatividade e argumentação. Revista do Programa de PósGraduação em Letras da Universidade de Passo Fundo, v. 9, nº 2, p. 271-283 $\mathrm{jul} / \mathrm{dez}, 2013$.

LAGAZZI, S. O desafio de dizer não. Campinas, Pontes, 1988.

ORLANDI, E. (1988). A Linguagem e o seu funcionamento: As Formas do Discurso. 6. ed. Campinas, SP: Pontes, 2011.

ORLANDI, E. Cidade dos Sentidos. Campinas, SP: Pontes, 2004.

ORLANDI, E Análise do discurso: princípios e procedimentos. 10. ed. Campinas, SP: Pontes, 2010.

PAYER, M. O. Memória da língua. Imigração e Nacionalidade. São Paulo: Ed. Escuta, 2006.

PFEIFFER, C. C. sentidos na cidade: clichê e sujeito urbano. Rua, v. 3, n. 1, p. 37-57, 1997. 
PFEIFFER, C. C. Cidade e sujeito escolarizado. In: ORLANDI, E. P. (Org.). Cidade atravessada: os sentidos públicos no espaço urbano. Pontes: 2001. p. 29- 33.

PRASSE, J. O desejo das línguas estrangeiras. Revista Internacional, ano $1, \mathrm{n}^{\mathrm{o}} 1$. Rio de Janeiro, Paris, Nova York, Buenos Aires, 1997.

SOARES, L. C. Rameiras, ilhoas, polacas. A prostituição no Rio de Janeiro no século XIX. São Paulo: Editora Ática, 1992. 120p .

ZOPPI FONTANA, Mónica. A Arte do Detalhe. In: Web Revista Discursividade, Estudos Linguísticos, Edição nº 9, Campo Grande, MS. 2012.

Data de Recebimento: 15/01/2018

Data de Aprovação: 23/05/2018 


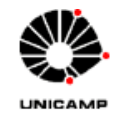

\section{Para citar essa obra:}

FRANCO, Wagner Ernesto Jonas., As casas de prostituição como espaços de significação na cidade In: RUA [online]. Volume 24, número 2 - p. 351-372 - e-ISSN 2179-9911 - novembro/2018. Consultada no Portal Labeurb - Revista do Laboratório de Estudos Urbanos do Núcleo de Desenvolvimento da Criatividade.

http://www.labeurb.unicamp.br/rua/

Capa: placa de identificação de uma casa de prostituição Fonte: http://www.tvminas.com/empresa-info/554/Sensacao_Drinks

Laboratório de Estudos Urbanos - LABEURB

Núcleo de Desenvolvimento da Criatividade - NUDECRI

Universidade Estadual de Campinas - UNICAMP

http://www.labeurb.unicamp.br/

Endereço:

LABEURB - LABORATÓRIO DE ESTUDOS URBANOS

UNICAMP/COCEN / NUDECRI

CAIXA POSTAL 6166

Campinas/SP - Brasil

CEP 13083-892

Fone/ Fax: (19) 3521-7900

Contato: http://www.labeurb.unicamp.br/contato 